\title{
Inhibition of in vitro maturation of equine oocytes by interleukin $1 \beta$ via specific IL-1 receptors
}

\author{
A. Martoriati, M. Caillaud, G. Goudet and N. Gérard* \\ Équipe Reproduction Équine, Unité de Physiologie de la Reproduction et des Comportements, \\ INRA 37380 Nouzilly, France
}

Interleukin $1 \beta$ (IL-1ß) inhibits the LH-induced resumption of meiosis of equine oocytes in vitro. The present study was performed to clarify this inhibitory effect of IL-1 $\beta$ by testing increasing concentrations of IL-1 $\beta$, and by measuring the effect of addition of IL-1 receptor antagonist (IL-1RA) to the culture medium. The effect of IL-1 $\beta$ on epidermal growth factor (EGF)-induced resumption of meiosis was also studied. Cumulus-oocyte complexes (COCs) were collected from subordinate follicles on ovaries obtained from an abattoir. In five distinct experiments, COCs were cultured for $30 \mathrm{~h}$ and nuclear maturation of oocytes was evaluated by DNA staining. In Expt 1, seven different media were tested: medium 1 (TCM199 + BSA); medium 2 (medium 1 + 50 ng IL-1 $\beta$ ml$^{-1}$ ); medium 3 (medium 1 + eLH); and media 4, 5, 6 and 7 (medium 3 containing $0.1,1.0,10.0$ and $50.0 \mathrm{ng} \mathrm{IL-1} \mathrm{ml}^{-1}$, respectively). In Expt 2, four different media were tested: medium 1 (TCM199 + BSA + eLH);

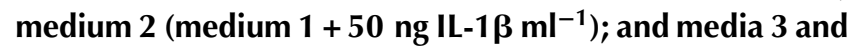
4 (medium $2+$ IL-1RA at 50 and $100 \mathrm{ng} \mathrm{ml}^{-1}$, respectively). In Expt 3, three different media were tested: medium 1 (TCM199 + BSA + eLH); medium 2 (medium $1+50$ ng IL$1 \mathrm{RA} \mathrm{ml}^{-1}$ ); and medium 3 (medium $2+50 \mathrm{ng} \mathrm{IL-1 \beta} \mathrm{ml}^{-1}$ ). In Expt 4, four different media were tested: medium 1 (TCM199 + BSA + eLH); and media 2, 3 and 4 (medium $1+$ IL-1RA at 50, 100 and $150 \mathrm{ng} \mathrm{ml}^{-1}$, respectively). In Expt 5, three different media were tested: medium 1 (TCM199 + BSA + EGF); medium 2 (medium $1+50 \mathrm{ng} \mathrm{IL-1 \beta} \mathrm{ml-1);} \mathrm{and}$ medium 3 (medium $2+50$ ng IL-1 RA ml ${ }^{-1}$ ). In Expt 1, LH alone induced an increase in the rate of in vitro maturation (IVM) of equine oocytes $(P<0.05)$, whereas IL-1 $\beta$ alone did not have any effect compared with medium 1. IL-1 $\beta$ (50 $\mathrm{ng} \mathrm{ml}^{-1}$ ) significantly inhibited the eLH-induced IVM of oocytes $(P<0.05)$ compared with medium 3. A decrease in rate of maturation was observed from a concentration of $10 \mathrm{ng} \mathrm{IL-1 \beta} \mathrm{ml} \mathrm{I}^{-1}$ onwards. In Expt 2, the presence of IL-1RA in the culture medium inhibited the effect of IL$1 \beta$ and restored the rate of oocyte maturation $(P<0.05)$ observed in the presence of LH alone. In Expts 3 and 4 it was demonstrated that IL-1RA alone had no positive effect on the eLH-induced rate of maturation. In Expt 5, IL-1 $\beta$ inhibited the EGF-induced resumption of meiosis $(P<0.05)$. The addition of IL-1RA inhibited this effect and restored the rate of oocyte maturation $(P<0.05)$ observed with EGF alone. In conclusion, the present data confirm the inhibitory effect of IL-1 $\beta$ on IVM of equine oocytes induced by eLH and demonstrate its inhibitory effect on EGF-induced oocyte maturation. The rate of maturation decreased in a dose-dependent way and the lowest rate of

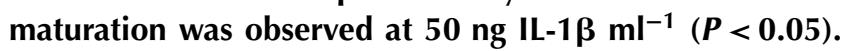
The use of IL-1RA inhibited these effects, demonstrating that the action of IL-1 $\beta$ is receptor-mediated. Moreover, the results clearly show that, in equine species, IL-1ß is involved in the physiology of COCs by regulating resumption of meiosis.

\section{Introduction}

Ovulation is assimilated to a cyclic inflammatory-like process (Espey, 1980) in which interleukin 1 (IL-1), an established mediator of inflammation, may play an intermediate role (Hurwitz et al., 1991). IL-1 is organized as a gene system including two bioactive ligands, (IL- $1 \alpha$ and IL-1 $\beta$; Dinarello, 1994), two types of receptor (IL-1R1 and IL-1R2; Colotta et al., 1991; Sims and Dower, 1994) and a natural receptor antagonist (IL-1RA) that regulates

*Correspondence

Email: gerard@tours.inra.fr the biological activity of IL-1 ligand (Arend, 1991). Several lines of evidence support the intermediate role of IL-1 at the ovarian follicle level. First, the supply of IL$1 \beta$ to an ex vivo-perfused ovary promotes ovulation in rat and rabbit models and synergizes with $\mathrm{LH}$ (Brännström et al., 1993a; Takehara et al., 1994). In parallel, the supply of IL-1RA attenuates LH-supported ovulation ex vivo (Peterson et al., 1993) and in vivo (Simon et al., 1994a). Second, the expression of some components of the intraovarian IL-1 system (for example, IL- $1 \alpha$, IL-1 $\beta$, IL1RA, IL-R1 and IL-1R2) was detected in ovarian follicles of rats (Hurwitz et al., 1991; Kol et al., 1999a,b,c), mice (Simon et al., 1994b), humans (Hurwitz et al., 1992; 
Chen et al., 2000) and mares (Martoriati et al., 2002; Martoriati and Gerard, 2003). Finally, IL-1 $\beta$ regulates several ovulation-associated events in vitro, such as the activation of nitric oxide synthase (Ben-Shlomo et al., 1994a,b) and the synthesis of proteases (Hurwitz et al., 1993), plasminogen activator (Bonello et al., 1995; Karakji and Tsang, 1995), hyaluronic acid (Kokia et al., 1993) and prostaglandins (Kokia et al., 1992; Brännström et al., 1993b) in the preovulatory follicle. Moreover, IL-1 ligands (IL-1 $\alpha$ and IL-1 $\beta$ ) stimulate gonadotrophinsupported steroidogenesis in rat, hamster and human granulosa cells (Gottschall et al., 1987; Nakamura et al., 1990; Best and Hill, 1995).

We recently tested the potential role of IL-1 $\beta$ on in vitro maturation (IVM) of equine oocytes to determine the involvement of IL-1 $\beta$ in ovarian cell function (Martoriati et al., 2002). IL-1 $\beta$ was found to display an inhibitory effect on the nuclear maturation of oocytes induced by equine LH (Martoriati et al., 2002). The aim of the present study was to clarify the action of IL-1 $\beta$ on nuclear maturation of equine oocytes in vitro. Thus, the inhibitory effect of increasing doses of IL-1 $\beta$ on LHinduced resumption of meiosis in vitro was studied; the effect of IL-1 $\beta$ on the EGF-induced rate of maturation of equine oocytes was also measured. Furthermore, the in vitro effect of IL-1RA alone or in the presence of IL-1 $\beta$ was investigated

\section{Materials and Methods}

\section{Recovery and culture of cumulus-oocyte complexes} (COCs)

Equine COCs were collected from ovaries at an abattoir (Goudet et al., 2000). Subordinate follicles were punctured and aspirated with an 18.5 gauge needle under $30 \mathrm{~mm} \mathrm{Hg}$ of vacuum pressure. The follicular fluids recovered during collection were maintained at $32^{\circ} \mathrm{C}$. After puncture, the follicular fluids were examined under a stereomicroscope for the presence of COCs. The morphology of the cumulus of recovered COCs was examined and they were classified as compact, expanded or denuded. Compact COCs were washed four times in PBS with gentamycin $\left(50 \mu \mathrm{g} \mathrm{ml}^{-1}\right.$; Sigma, Saint Quentin Fallavier) and once in maturation medium (see below). The COCs were cultured individually in a humidified atmosphere $\left(95 \%\right.$ air and $\left.5 \% \mathrm{CO}_{2}\right)$ at $38.5^{\circ} \mathrm{C}$ for $30 \mathrm{~h}$ in $20 \mu \mathrm{l}$ maturation medium covered with mineral oil (Sigma).

\section{Examination of nuclear stage of oocytes}

After culture, the COCs were rinsed twice in PBS at $37^{\circ} \mathrm{C}$ and their cumulus cells were stripped off with a small glass pipette. Totally denuded oocytes were rinsed once in PBS and DNA was stained with $1 \mu \mathrm{g}$ bis-benzimide solution $\mathrm{ml}^{-1}$ (Hoechst 33342; Sigma).
The oocytes were observed in a droplet on a slide under both a light and a fluorescence microscope to determine the nuclear stage. Oocytes with a polar body, an intact membrane (light microscopy) and two distinct spots of chromosomes stained by Hoechst (fluorescence microscopy) were considered to be in metaphase II (Goudet et al., 1997).

\section{Experiment 1: effect of dose of $I L-1 \beta$ on rate of nuclear IVM}

Seven different maturation media were used. Medium 1 contained tissue culture medium 199 (TCM-199; Sigma) supplemented with $0.5 \%(\mathrm{w} / \mathrm{v})$ BSA (Sigma). Media 2 and 3 contained medium 1 supplemented with either recombinant human interleukin-1 $\beta$ (rhIL-1 $\beta$; Eurobio, Les Ulis; $50 \mathrm{ng} \mathrm{m}^{-1}$; medium 2) or equine LH (eLH; NIH, Bethesda, MD; $5 \mu \mathrm{g} \mathrm{m}{ }^{-1}$; medium 3). Media 4, 5, 6 and 7 were composed of medium 3 supplemented with $0.1,1.0,10.0$ and $50.0 \mathrm{ng}$ rhIL-1 $\beta$ $\mathrm{ml}^{-1}$, respectively.

\section{Experiment 2: effect of IL-1RA on nuclear IVM of oocytes exposed to IL-1 $\beta$}

Four maturation media were used. Medium 1 contained TCM-199 supplemented with $0.5 \%(\mathrm{w} / \mathrm{v}) \mathrm{BSA}$ and $5 \mu \mathrm{g}$ eLH ml $\mathrm{ml}^{-1}$. Medium 2 was composed of medium 1 supplemented with $50 \mathrm{ng}$ rhIL-1 $\beta \mathrm{ml}^{-1}$. Media 3 and 4 contained medium 2 supplemented with 50 and 100 ng recombinant human IL-1RA ml ${ }^{-1}$ (rhIL-1RA; R and D systems, Abington), respectively.

\section{Experiment 3: effect of IL-1RA on rate of nuclear IVM}

Three maturation media were used. Medium 1 was TCM-199 supplemented with $0.5 \%(\mathrm{w} / \mathrm{v}) \mathrm{BSA}$ and $5 \mu \mathrm{g}$ $\mathrm{eLH} \mathrm{ml}^{-1}$. Medium 2 was composed of medium 1 supplemented with rhIL-1RA (50 $\mathrm{ng} \mathrm{ml}^{-1}$ ). Medium 3 was medium 2 supplemented with $50 \mathrm{ng}$ rhlL-1 $\beta \mathrm{ml}^{-1}$.

\section{Experiment 4: effect of dose of IL-1RA on rate of nuclear IVM}

Four maturation media were used. Medium 1 was TCM-199 supplemented with $0.5 \%(\mathrm{w} / \mathrm{v}) \mathrm{BSA}$ and $5 \mu \mathrm{g}$ eLH ml ${ }^{-1}$. Media 2, 3 and 4 were composed of medium 1 supplemented with 50, 100 and $150 \mathrm{ng} \mathrm{rhIL-1RA} \mathrm{ml}^{-1}$, respectively.

Experiment 5: effect of IL-1 $\beta$ on nuclear IVM of oocytes induced by EGF

Three different maturation media were used. Medium 1 contained TCM-199 supplemented with $0.5 \%$ $(\mathrm{w} / \mathrm{v}) \mathrm{BSA}$ and $50 \mathrm{ng}$ mouse epidermal growth factor $\mathrm{ml}^{-1}$ (EGF; Sigma). Media 2 and 3 contained medium 1 supplemented with either $50 \mathrm{ng} \mathrm{rhlL}-1 \beta \mathrm{ml}^{-1}$ (medium 2) 


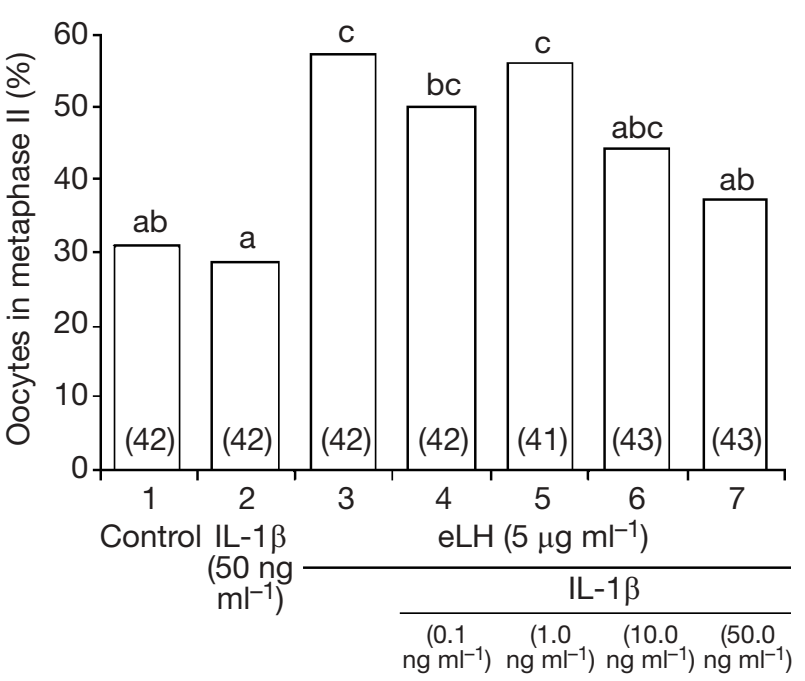

Fig. 1. Effect of interleukin $1 \beta$ (IL-1 $\beta$ ) on nuclear in vitro maturation of equine oocytes induced by eLH. Medium 1 contained TCM-199 supplemented with $0.5 \%(\mathrm{w} / \mathrm{v})$ BSA. Media 2 and 3 contained medium 1 supplemented with either recombinant human IL-1 $\beta$ (rhIL-1 $\beta$; $50 \mathrm{ng} \mathrm{ml}^{-1}$; medium 2 ) or equine $\mathrm{LH}(\mathrm{eLH}$; $5 \mu \mathrm{g} \mathrm{ml}^{-1}$; medium 3). Media 4, 5, 6 and 7 were composed of medium 3 supplemented with $0.1,1.0,10.0$ and $50.0 \mathrm{ng}$ rhlL$1 \beta \mathrm{ml}^{-1}$, respectively. The histogram represents the percentage of oocytes in metaphase II. The number of oocytes analysed in each medium is indicated in brackets at the bottom of each bar. ${ }^{a-c}$ Different letters indicate significant differences according to the Pearson's chi-squared test $(P<0.05)$.

or $50 \mathrm{ng}$ rhIL-1 $\beta \mathrm{ml}^{-1}$ and $50 \mathrm{ng}$ rhIL-1RA ml ${ }^{-1}$ (medium 3).

\section{Statistical analysis}

In each experiment, the Pearson's chi-squared test was performed to compare rates of oocyte maturation using StatXact 5 software (CYTEL, Cambridge, MA; www.cytel.com).

\section{Results}

Experiment 1: effect of dose of IL-1 $\beta$ on rate of nuclear IVM

A total of 295 COCs from 102 ovaries was used in this experiment. Increasing doses of IL-1 $\beta$ were tested on equine oocytes. The rate of oocyte maturation was not significantly different between medium 1 , which contained BSA only (control medium), and medium 2,

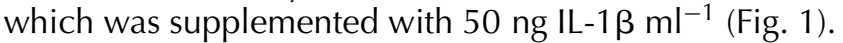
The rate of oocyte maturation was significantly higher in medium 3, which contained eLH, than in media 1 and $2(P<0.05)$. Addition of IL-1 $\beta$ to the culture medium containing eLH resulted in a dose-dependent decrease in rate of oocyte maturation from a concentration of 10

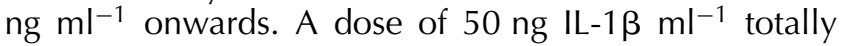

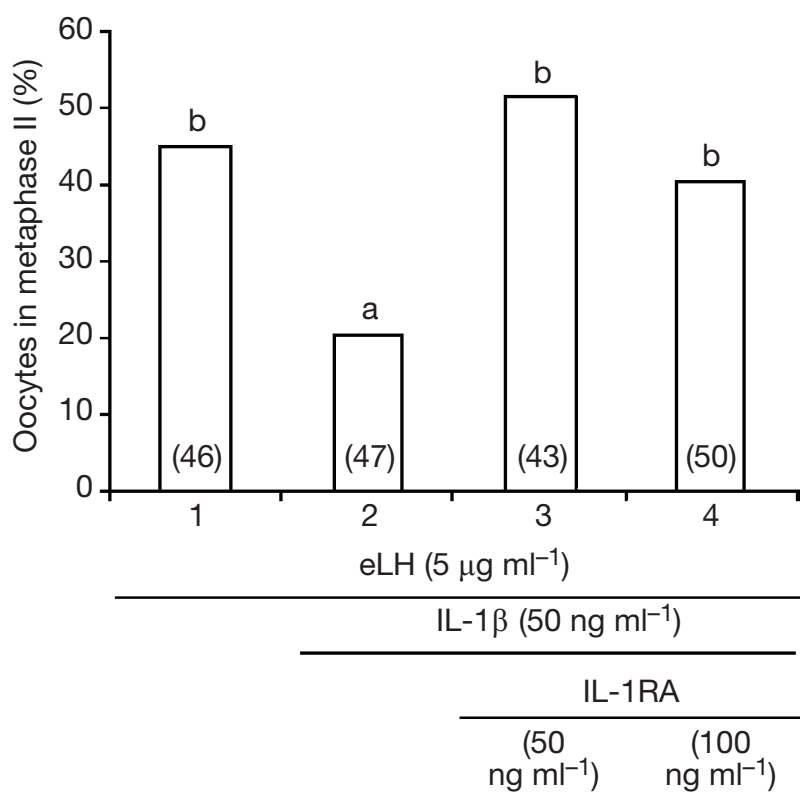

Fig. 2. Effect of interleukin 1 receptor antagonist (IL-1RA) on nuclear in vitro maturation of equine oocytes in the presence of eLH and IL-1 $\beta$. Medium 1 contained TCM-199 supplemented with

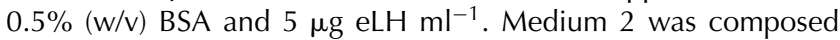
of medium 1 supplemented with 50 ng recombinant human IL$1 \beta \mathrm{ml}^{-1}$. Media 3 and 4 contained medium 2 supplemented with 50 and $100 \mathrm{ng}$ recombinant human IL-1RA ml-1 (rhlL-1RA), respectively. The histogram represents the percentage of oocytes in metaphase II. The number of oocytes analysed in each medium is indicated in brackets at the bottom of each bar. ${ }^{a b}$ DIfferent letters indicate significant differences according to the Pearson's chi-squared test $(P<0.05)$.

inhibited the positive effect of LH on oocyte maturation. Indeed, similar rates of maturation were observed in medium 1 and medium 7.

\section{Experiment 2: effect of IL-1RA on nuclear IVM of oocytes exposed to IL-1及}

A total of 186 COCs from 58 ovaries was used in this experiment. As observed in Expt 1, the rate of oocyte maturation was significantly higher in medium 1 , which contained eLH, than in medium 2, which contained eLH and $50 \mathrm{ng} \mathrm{IL}-1 \beta \mathrm{ml}^{-1}(P<0.05$; Fig. 2). Addition of IL$1 \mathrm{RA}$ at $50 \mathrm{ng} \mathrm{ml}^{-1}$ (medium 3) or $100 \mathrm{ng} \mathrm{ml}^{-1}$ (medium 4) significantly increased the rate of oocyte maturation compared with medium $2(P<0.05)$, and restored the rate of maturation to that observed in medium 1 .

\section{Experiment 3: effect of IL-1RA on rate of nuclear IVM}

A total of 118 COCs from 46 ovaries was used in this experiment. Despite a slight increase in medium 2 (eLH + IL-1RA), the rates of maturation were similar in the three media tested (Fig. 3). This finding demonstrates that IL-1RA, in the absence of IL-1 $\beta$, has no effect on $\mathrm{LH}$-induced oocyte maturation. 


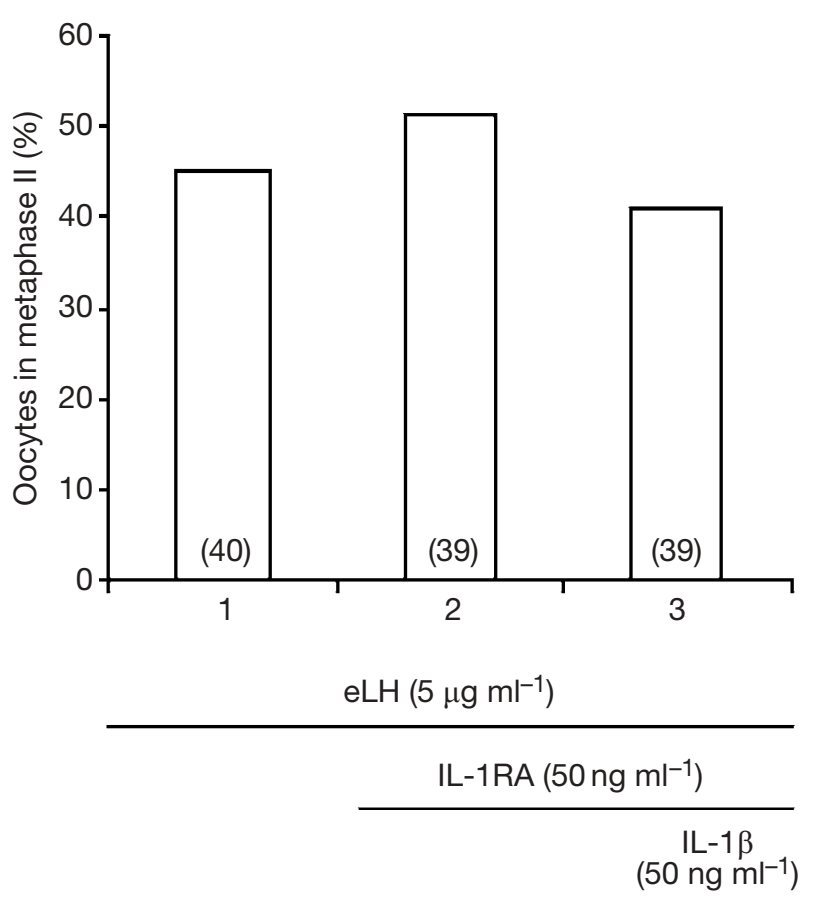

Fig. 3. Effect of interleukin 1 receptor antagonist (IL-1RA) on nuclear in vitro maturation of equine oocytes induced by eLH $\left(5 \mu \mathrm{g} \mathrm{m} \mathrm{m}^{-1}\right.$ ). Medium 1 was TCM-199 supplemented with $0.5 \%(\mathrm{w} / \mathrm{v}) \mathrm{BSA}$ and $5 \mu \mathrm{g}$ eLH $\mathrm{ml}^{-1}$. Medium 2 was composed of medium 1 supplemented with recombinant human IL-1RA (rhILIRA, $50 \mathrm{ng} \mathrm{ml}^{-1}$ ). Medium 3 was medium 2 supplemented with $50 \mathrm{ng}$ rhlL-1 $\beta \mathrm{ml}^{-1}$. The histogram represents the percentage of oocytes in metaphase II. The number of oocytes analysed in each medium is indicated in brackets at the bottom of each bar. No significant difference between groups was observed (Pearson's chisquared test).

\section{Experiment 4: effect of dose of IL-1RA on rate of nuclear IVM}

A total of 181 COCs from 40 ovaries was used in this experiment. The rate of oocyte maturation was not different between medium 1, which contained eLH alone (control medium), and media 2 and 3, which were supplemented with IL-1RA at 50 and $100 \mathrm{ng} \mathrm{ml}^{-1}$, respectively (Fig. 4). The rate of oocyte maturation was significantly decreased in medium 4 , which contained the highest concentration of IL-1RA (150 ng ml-1; $P<0.05)$. This finding confirms that IL-1RA has no positive effect on $\mathrm{LH}$-induced oocyte maturation.

\section{Experiment 5: effect of IL-1 $\beta$ on nuclear IVM of oocytes induced by EGF}

A total of 95 COCs from 28 ovaries was used in this experiment. Addition of IL-1 $\beta$ (50 $\mathrm{ng} \mathrm{ml}^{-1}$ ) to COCs in the presence of EGF resulted in a significant decrease in the rate of oocyte maturation $(P<0.01$; Fig. 5). IL-1RA at a concentration of $50 \mathrm{ng} \mathrm{ml}^{-1}$ inhibited this negative

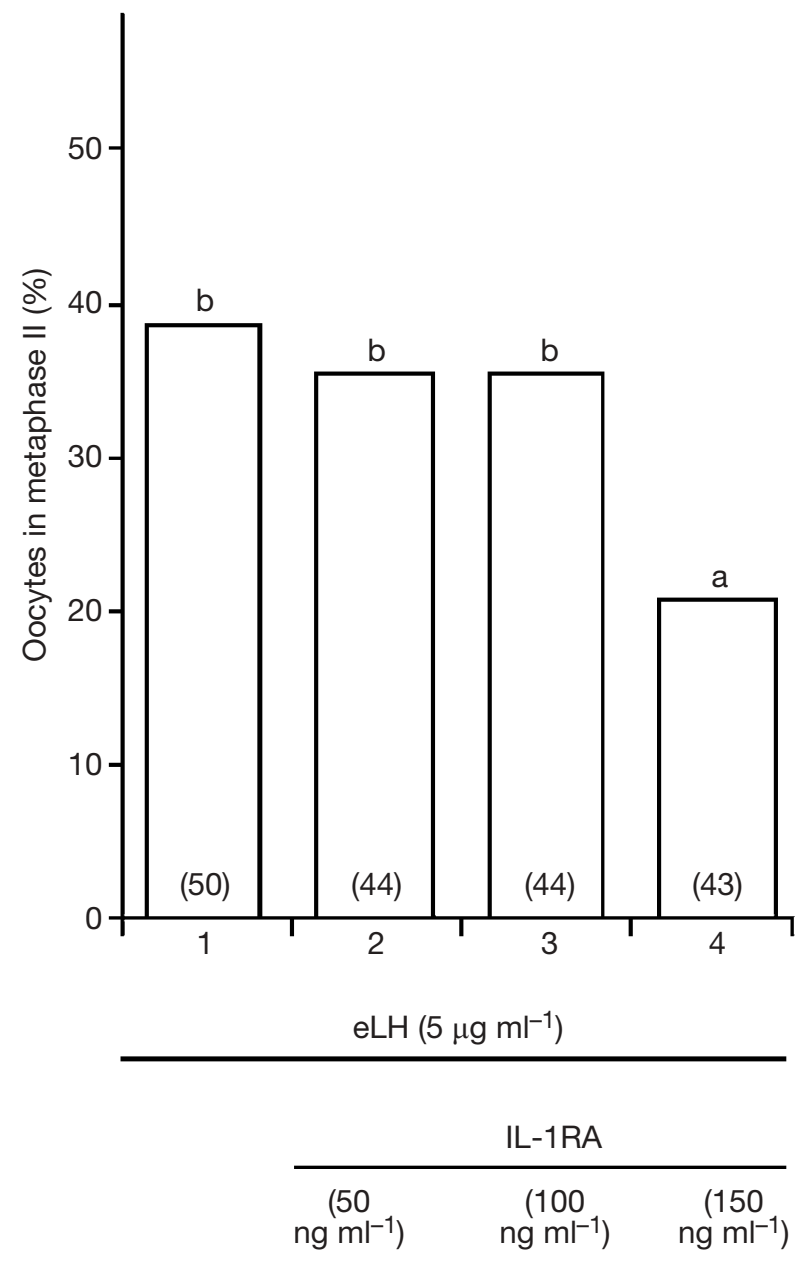

Fig. 4. Effect of dose of interleukin 1 receptor antagonist (IL-1RA) on nuclear in vitro maturation of equine oocytes induced by eLH $\left(5 \mu \mathrm{g} \mathrm{ml}^{-1}\right.$ ). Medium 1 was TCM-199 supplemented with $0.5 \%$

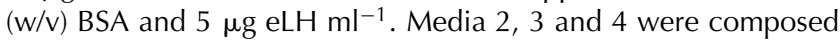
of medium 1 supplemented with 50, 100 and 150 ng recombinant human IL-1RA $\mathrm{ml}^{-1}$, respectively. The histogram represents the percentage of oocytes in metaphase II. The number of oocytes analysed in each medium is indicated in brackets at the bottom of each bar. ${ }^{a b}$ DIfferent letters indicate significant differences according to the Pearson's chi-squared test $(P<0.05)$.

effect and restored the rate of maturation to that observed in medium 1, which contained EGF only.

\section{Discussion}

Martoriati et al. (2002) demonstrated that IL-1 $\beta$ inhibits the eLH-induced resumption of meiosis of equine oocytes in vitro. The aim of the present study was to clarify this inhibitory effect.

Expt 1 was designed to determine the lowest dose of IL-1 $\beta$ that is required to inhibit eLH-induced oocyte maturation. The results demonstrate that completion of meiosis is influenced by IL-1 $\beta$ in a dose-dependent way. The inhibitory effect was observed from $10 \mathrm{ng} \mathrm{ml}^{-1}$ 
onwards and was significant at $50 \mathrm{ng} \mathrm{ml}^{-1}$. It is possible that IL-1 $\beta$ may act directly on LH or on its receptor. This hypothesis was tested by investigating the effect of IL-1 $\beta$ in the presence of EGF, another factor involved in IVM of oocytes (Goudet et al., 2000). In Expt 5 it was observed that IL-1 $\beta$ inhibited the resumption of meiosis induced by EGF as observed with LH. This finding indicates that IL-1 $\beta$ may be involved in the regulation of meiosis downstream of the LH and EGF receptors rather than on the LH signal transduction, as was suggested in our previous work (Martoriati et al., 2002). Although the mechanism by which IL-1 $\beta$ regulates oocyte maturation is unclear, it can be hypothesized that IL-1 $\beta$ could act at a common pathway between $\mathrm{LH}$ and EGF, and inhibit resumption of meiosis. Indeed, IL-1 $\beta$ could exert an effect on meiosis by regulating the synthesis or the activity of some key proteins such as $\mathrm{p} 34 \mathrm{cdc} 2$, cycline B or MAP kinase.

IL-1 $\beta$ concentration in follicular fluid has been measured at between $53 \mathrm{pg} \mathrm{ml}^{-1}$ and $255 \mathrm{pg} \mathrm{ml}^{-1}$ in humans (Machelon et al., 1995), and the production of IL-1 $\beta$ by granulosa cells in culture has been estimated at $350 \mathrm{pg} \mathrm{ml}^{-1}(24 \mathrm{~h})^{-1}$. No data are available on the intrafollicular concentration of IL-1 $\beta$ in horses, but the results of the present study show that IL-1 $\beta$ influences IVM of equine oocytes from $10 \mathrm{ng} \mathrm{ml}^{-1}$ onwards. This dose is higher than the intrafollicular physiological concentration measured so far in humans (Machelon et al., 1995) but corresponds to the dose used to study the effect of IL-1ßon human steroidogenesis in vitro (Best and Hill, 1995) and on biosynthesis of rat ovarian prostaglandins (Ando et al., 1998). Moreover, it is possible that the effective dose used in vitro in the present study could be explained by some speciesspecific features. Indeed, it has already been shown in the equine species that in vivo maturation conditions are somewhat different from those in other mammals: there is no LH surge, but a slow increase lasting several days, with a maximum value observed at 1 day after ovulation (Whitmore et al., 1973; Irvine and Alexander, 1994).

The aim of the second part of the present study was to determine how IL-1 $\beta$ acts on oocyte maturation. IL-1RA is a competitive inhibitor of the actions of both IL- $1 \alpha$ and IL-1 $\beta$. It regulates IL- 1 ligand biological activity by binding to IL-1 receptors without inducing any cellular effect (Hannum et al., 1990; Arend, 1991; Dripps et al., 1991). In several studies, IL-1RA has been used to demonstrate that the effect of IL-1 $\beta$ is mediated via IL-1specific receptors. For example, the presence of IL-1RA in culture media limits IL-1 $\beta$ fixation on its receptor and thus limits the effect of IL-1 $\beta$ on prostaglandin production by human (Hurwitz et al., 1995) and rat (Ando et al., 1998) granulosa cells. In Expt 2, IL-1RA was used in the culture media and it was observed that IL-1RA reversed the inhibitory effect of IL-1 $\beta$ on the oocyte maturation induced by LH. However, in Expt 5 it was shown that IL1 RA neutralized the IL-1 $\beta$ inhibitory effect and restored the EGF positive action on oocyte maturation. Moreover,

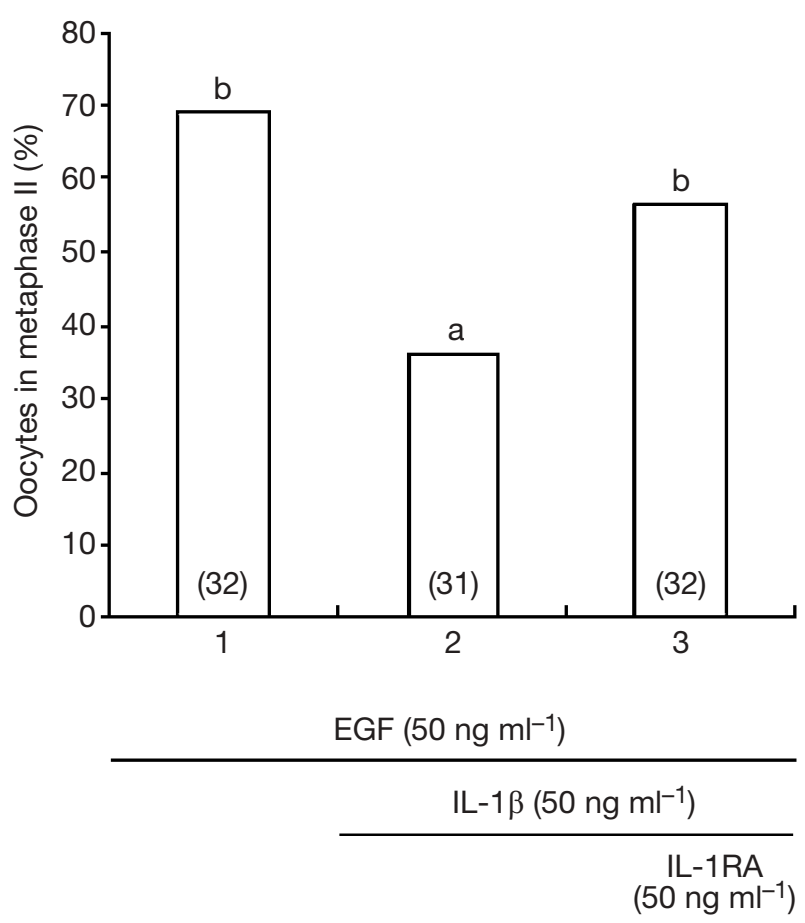

Fig. 5. Effect of interleukin $1 \beta$ (IL-1 $\beta$ ) and interleukin 1 receptor antagonist (IL-1RA) on nuclear in vitro maturation of equine oocytes induced by epidermal growth factor (EGF). Medium 1 contained TCM-199 supplemented with $0.5 \%(\mathrm{w} / \mathrm{v})$ BSA and $50 \mathrm{ng}$ mouse EGF $\mathrm{ml}^{-1}$. Media 2 and 3 contained medium 1 supplemented with either $50 \mathrm{ng}$ recombinant human IL-1 $\beta$ (rhIL-

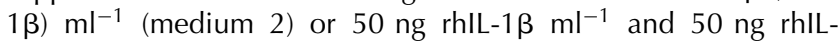
$1 \mathrm{RA} \mathrm{m} \mathrm{m}^{-1}$ (medium 3). The histogram represents the percentage of oocytes in metaphase II. The number of oocytes analysed in each medium is indicated in brackets at the bottom of each bar. ${ }^{a-c}$ DIfferent letters indicate significant differences according to the Pearson's chi-square test $(P<0.05)$.

equine oocytes expressed IL-1R2 and cumulus cells expressed the two types of IL-1 receptor (IL-1R1 and IL1R2; Martoriati et al., 2002). Taken together, these results demonstrate that the inhibitory effect of IL-1 $\beta$ on oocyte maturation is receptor-mediated and is a biological effect of IL-1 $\beta$ rather than a cytotoxic effect of IL-1 $\beta$ in the culture conditions used.

As equine COCs contain IL-1 $\beta$ mRNA (Martoriati et al., 2002), it can be hypothesized that COCs are capable of producing some biologically active IL-1 $\beta$. This local IL-1 $\beta$ could then interact with eLH or EGF and thus limit the rate of oocyte maturation in the culture conditions used. This hypothesis was tested in Expts 3 and 4 of the present study. In both experiments, IL$1 R A$ was added to the culture medium containing $\mathrm{LH}$ to neutralize the potential inhibitory action of some locally produced IL-1 $\beta$. In Expt 3, a slight, but not significant, positive effect of IL-1RA (50 $\mathrm{ng} \mathrm{ml}^{-1}$ ) on the rate of oocyte maturation induced by eLH was observed. In Expt 4, the supplementation of culture medium with IL$1 \mathrm{RA}$ at 50 and $100 \mathrm{ng} \mathrm{ml}^{-1}$ confirmed the absence of a 
positive effect of IL-1RA on the rate of oocyte maturation induced by eLH. This observation could be explained by the absence of active IL-1 $\beta$ production by COCs in the culture conditions used. It is possible that the IL $1 \beta \mathrm{mRNA}$ that is present in equine COCs (Martoriati et al., 2002) may not be translated (or is translated at very low level), or is translated in a non-biologically active protein, or is not secreted. Thus, the effect of IL-1RA cannot be visualized. The absence of a positive effect of IL-1RA on rate of oocyte maturation induced by eLH can also be explained by the fact that the rate of maturation cannot be increased in our culture conditions, as non-matured oocytes are incompetent to resume IVM. Finally, considering that equine COCs contained some IL-1RA mRNA (Martoriati et al., 2002), the absence of a significant effect of IL1 RA might also be explained by the neutralization of endogenous IL- $1 \beta$ by some locally produced IL-1RA. The significant decrease in rate of maturation was observed in medium supplemented with IL-1RA at $150 \mathrm{ng} \mathrm{ml}^{-1}$, indicating that IL-1RA probably has a cytotoxic effect at high concentration.

In conclusion, the results of the present study confirm that IL-1 $\beta$ has an inhibitory effect on the IVM of equine oocytes induced by eLH. This effect is dose-dependent and is significant at a dose of $50 \mathrm{ng} I L-1 \beta \mathrm{ml}^{-1}$. The use of IL-1RA allowed us to demonstrate indirectly that IL-1 $\beta$ acts by binding to specific IL- 1 receptors. Finally, the inhibitory effect of IL-1 $\beta$ was not exclusive to eLH, as it was also observed with EGF. This result indicates that the action of IL-1 $\beta$ is probably on the regulation of meiosis. Although the mechanism by which IL-1 $\beta$ regulates oocyte maturation is unclear, the IL-1 family may play an essential role in the physiology of COCs in equine species.

The authors would like to thank C. Lahuec, M. Musset and A. Dabert for technical assistance. Equine LH was generously provided by NIDDK's National Hormone \& Pituitary Program (A. F. Parlow, NIH).

\section{References}

Ando M, Kol S, Kokia E, Ruutiainen-Altman K, Sirois J, Rohan RM, Payne DW and Adashi EY (1998) Rat ovarian prostaglandin endoperoxide synthase-1 and -2: periovulatory expression of granulosa cell-based interleukin-1-dependent enzymes Endocrinology 139 2501-2508

Arend WP (1991) Interleukin 1 receptor antagonist. A new member of the interleukin 1 family Journal of Clinical Investigation 88 1445-1451

Ben-Shlomo I, Adashi EY and Payne DW (1994a) The morphogenic/ cytotoxic and prostaglandin-stimulating activities of interleukin-1 beta in the rat ovary are nitric oxide independent Journal of Clinical Investigation 94 1463-1469

Ben-Shlomo I, Kokia E, Jackson MJ, Adashi EY and Payne DW (1994b) Interleukin-1 beta stimulates nitrite production in the rat ovary: evidence for heterologous cell-cell interaction and for insulin-mediated regulation of the inducible isoform of nitric oxide synthase Biology of Reproduction $51310-318$

Best CL and Hill JA (1995) Interleukin- $1 \alpha$ and $-\beta$ modulation of luteinized human granulosa cell oestrogen and progesterone biosynthesis Human Reproduction 10 3206-3210
Bonello NP, Norman RJ and Brännström M (1995) Interleukin-1 $\beta$ inhibits luteinizing hormone-induced plasminogen activator activity in rat preovulatory follicles Endocrine 3 49-54

Brännström M, Wang L and Norman RJ (1993a) Ovulatory effect of interleukin-1 on the perfused rat ovary Endocrinology 132 399-404

Brännström M, Wang L and Norman RJ (1993b) Effects of cytokines on prostaglandin production and steroidogenesis of incubated preovulatory follicles of the rat Biology of Reproduction 48 165-170

Chen HF, Shew JY, Chao KH, Chang LJ, Ho HN and Yang YS (2000) Luteinizing hormone up-regulates the expression of interleukin-1 beta mRNA in human granulosa-luteal cells American Journal of Reproductive Immunology 43 125-133

Colotta F, Dower SK, Sims JE and Mantovani A (1991) The type II "decoy" receptor: a novel regulatory pathway for interleukin-1 Immunology Today 15 562-566

Dinarello CA (1994) The interleukin-1 family: 10 years of discovery FASEB Journal 8 1314-1325

Dripps DJ, Brandhuber BJ, Thompson RC and Eisenberg SP (1991) Interleukin-1 (IL-1) receptor antagonist binds to the 80-kDa IL-1 receptor but does not initiate IL-1 signal transduction Journal of Biological Chemistry $26610331-10336$

Espey LL (1980) Ovulation as an inflammatory reaction - a hypothesis Biology of Reproduction 22 73-106

Gottschall PE, Uehara A, Hoffmann ST and Arimura A (1987) Interleukin1 inhibits follicle stimulating hormone-induced differentiation in rat granulosa cells in vitro. Biochemical and Biophysical Research Communications 149 502-509

Goudet G, Bézard J, Duchamp G, Gérard N and Palmer E (1997) Equine oocyte competence for nuclear and cytoplasmic in vitro maturation: effect of follicle size and hormonal environment Biology of Reproduction $57232-245$

Goudet G, Belin F, Mlodawska W and Bézard J (2000) Influence of epidermal growth factor on in vitro maturation of equine oocytes Journal of Reproduction and Fertility Supplement 56 483-492

Hannum CH, Wilcox CJ, Arend WP et al. (1990) Interleukin-1 receptor antagonist activity of a human interleukin-1 inhibitor Nature 343336 340

Hurwitz A, Ricciarelli E, Botero L, Rohan RM, Hernandez ER and Adashi EY (1991) Endocrine- and autocrine-mediated regulation of rat ovarian (theca-interstitial) interleukin-1 $\beta$ gene expression: gonadotropin-dependent preovulatory acquisition Endocrinology 129 $3427-3429$

Hurwitz A, Loukides J and Ricciarelli E (1992) Human intraovarian interleukin-1 (IL-1) system: highly-compartmentalized and hormonallydependent regulation of the genes encoding IL-1, its receptor, and its receptor antagonist Journal of Clinical Investigation 89 1746-1754

Hurwitz A, Dushnik M, Solomon H, Ben-Chetrit A, Finci-Yeheskel Z, Milwidsky A, Mayer MD, Adashi EY and Yagel S (1993) Cytokinemediated regulation of rat ovarian function: interleukin-1 stimulates the accumulation of a 92-kilodalton gelatinase Endocrinology 1322709 2714

Hurwitz A, Finci-Yeheskel Z, Dushnik M, Milwidsky A, Shimonovitz S, Yagel S, Adashi EY and Mayer M (1995) Interleukin-1-mediated regulation of plasminogen activation in pregnant mare serum gonadotropin-primed rat granulosa cells is independent of prostaglandin production Journal of the Society of Gynecological Investigation 2 691-699

Irvine CHG and Alexander SL (1994) The dynamics of gonadotrophinreleasing hormone, $\mathrm{LH}$ and $\mathrm{FSH}$ secretion during the spontaneous ovulatory surge of the mare as revealed by intensive sampling of pituitary venous blood Journal of Endocrinology 140 283-295

Karakji EG and Tsang BK (1995) Regulation of rat granulosa cell plasminogen activator system: influence of interleukin-1 $\beta$ and ovarian follicular development Biology of Reproduction 53 1302-1310

Kokia E, Hurwitz A, Ricciarelli E, Tedeschi C, Resnick CE, Mitchell MD and Adashi EY (1992) Interleukin-1 stimulates ovarian prostaglandin biosynthesis: evidence for heterologous contact-independent cell-cell interaction Endocrinology 130 3095-3097

Kokia E, Hurwitz A, Ben-Shlomo I, Adashi EY and Yanagishita M (1993) Receptor-mediated stimulatory effect of IL-1 beta on hyaluronic acid 
and proteoglycan biosynthesis by cultured rat ovarian cells: role for heterologous cell-cell interactions Endocrinology 133 2391-2394

Kol S, Ruutiainen-Altman K, Scherzer WJ, Ben-Shlomo I, Ando M, Rohan RM and Adashi EY (1999a) The rat intraovarian interleukin (IL)-1 system: cellular localization, cyclic variation and hormonal regulation of IL$1 \beta$ and of the type I and II IL-1 receptors Molecular and Cellular Endocrinology 149 115-128

Kol S, Donesky BW, Ruutiainen-Altman K, Ben-Shlomo I, Irahara M, Ando M, Rohan RM and Adashi EY (1999b) Ovarian interleukin-1 receptor antagonist in rats: gene expression, cellular localization, cyclic variation, and hormonal regulation of a potential determinant of interleukin-1 action Biology of Reproduction 61 274-282

Kol S, Wong KH, Ando M, Ben-Shlomo I and Adashi EY (1999c) Rat ovarian interleukin-1 $\alpha$ : interleukin-1-dependent in vitro expression Endocrine 11 269-275

Machelon V, Nome F, Durand-Gasselin I and Emilie D (1995) Macrophage and granulosa interleukin-1 beta mRNA in human ovulatory follicles Human Reproduction 10 2198-2203

Martoriati A and Gerard N (2003) Interleukin-1 (IL-1) system genes expression in granulosa cells: kinetics during terminal preovulatory follicle maturation in the mare Reproductive Biology and Endocrinology 142 (http://www.rbej.com/content/pdf/1477-7827-1-42.pdf)

Martoriati A, Lalmanach AC, Goudet G and Gerard N (2002) Expression of interleukin-1 (IL-1) system genes in equine cumulus-oocyte complexes and influence of IL-1 $\beta$ during in vitro maturation Biology of Reproduction 67 630-636

Nakamura Y, Kato H and Terranova PF (1990) Interleukin- $1 \alpha$ increases thecal progesterone production of preovulatory follicles in cyclic hamsters Biology of Reproduction 43 169-173
Peterson CM, Hales HA, Hatasaka HH, Mitchell MD, Rittenhouse L and Jones KP (1993) Interleukin-1 $\beta$ (IL-1 $\beta$ ) modulates prostaglandin production and the natural IL-1 receptor antagonist inhibits ovulation in the optimally stimulated rat ovarian perfusion model Endocrinology 133 2301-2306

Simon C, Tsafriri A, Chun S-Y, Piquette GN, Dang W and Polan ML (1994a) Interleukin-1 receptor antagonist suppresses hCG-induced ovulation in the rat Biology of Reproduction 51 662-667

Simon C, Frances A, Piquette G and Polan ML (1994b) Immunohistochemical localization of the interleukin-1 system in the mouse ovary during follicular growth, ovulation, and luteinization Biology of Reproduction 50 449-457

Sims JE and Dower SK (1994) Interleukin-1 receptors European Cytokine Network 5 539-546

Takehara Y, Dharmarajan AM, Kaufman G and Wallach EE (1994) Effects of interleukin-1 $\beta$ on ovulation in the in vitro perfused rabbit ovary Endocrinology 134 1788-1793

Whitmore HL, Wentworth BC and Ginther OJ (1973) Circulating concentrations of luteinizing hormone during estrous cycle of mares as determined by radioimmunoassay American Journal of Veterinary Research 34 631-636

Received 13 November 2002.

First decision 19 December 2002.

Revised manuscript received 20 June 2003.

Accepted 25 June 2003. 